\title{
A study of migraine in systemic lupus erythematosus
}

\author{
DAVID A. ISENBERG, ${ }^{1}$ DIANNE MEYRICK-THOMAS, 1 \\ MICHAEL L. SNAITH, ${ }^{1}$ RONALD O. MCKERAN, ${ }^{2}$ AND \\ J. PATRICK ROYSTON ${ }^{3}$
}

From the ${ }^{1}$ Departments of Rheumatology and Haematology, University College Hospital, London; ${ }^{2}$ Atkinson Morley's Hospital, London; and the ${ }^{3}$ Division of Computing and Statistics, Clinical Research Centre, Harrow, Middlesex

SUMMARY An increased prevalence of classical migraine was found in 30 female patients with systemic lupus erythematosus (SLE) compared with an age and sex-matched control group by means of a detailed questionnaire. No significant differences were found between the patients and controls, who had classical and common migraine or visual auras without headache, with regard to a family history of migraine, the age of onset of the migraine, Raynaud's phenomenon, or use of oral contraceptives. Increased activity of the lupus was not generally associated with an increase in migraine attacks. It is suggested that migrainous phenomena may be a feature of SLE.

Although Brandt and Lessell ${ }^{1}$ reviewed migrainous phenomena in systemic lupus erythematosus (SLE), the prevalence of migrainous and other headaches in this disorder appears to have received scant attention. Atkinson and Appenzeller ${ }^{2}$ in a retrospective review studied the notes of 61 patients with SLE and found no difference in the incidence of headache between those patients with and without central nervous systemic lupus.

It was the clinical impression of one of us (MLS) that migrainous headaches were more common in patients with SLE. In order to test the hypothesis a detailed questionnaire was constructed and given to 30 lupus patients and 30 controls.

\section{Materials and methods}

The questionnaire established the age of onset of SLE (which was defined as when the patient was informed of the diagnosis) and inquired into any history of previous or current, classical or common migraine. Classical migraine was considered to be present when a frequently unilateral throbbing headache, usually associated with nausea, vomiting, and photophobia, was preceded or accompanied by an aura which could be visual, motor, or sensory. Common migraine was defined as a throbbing

Accepted for publication 19 January 1981.

Correspondence to Dr M. L. Snaith, Department of Rheumatology and Rehabilitation, University College Hospital, Gower Street, London WC1E 6AU. headache, less often strictly unilateral, though often accompanied by nausea, vomiting, and photophobia, which was not preceded or accompanied by an aura.

A family history of migraine was sought and whether the patient's migraine (classical or common) had become worse since the diagnosis of SLE or had increased with a flare of SLE activity. Questions were also asked about the previous or current use of oral contraception and whether Raynaud's phenomenon was present and if so whether its severity was related to the frequency and severity of migraine headaches. A history of any previous or current drug therapy was taken.

It was calculated that on the basis of an expected difference of $25 \%$ in the prevalence of migraine in SLE and controls a total sample of 60 subjects would be required in order to give an $80 \%$ chance of detecting the difference in prevalence at the $5 \%$ level of significance.

The questionnaire was therefore given to 30 female patients with lupus (25 Caucasian, 2 West Indian, and 3 Asian). Each patient had 4 or more of the American Rheumatism Association's criteria for the classification of SLE. ${ }^{3}$ Thirty female controls, mostly women at first attendance in the obstetric unit, were also questioned. The mean age of the SLE patients was 35.6 years (range 17-58, SD 9.5 years) and that of the controls $29 \cdot 5$ years (range 19-42, SD 6.6 years). The controls were asked to confine their answers to the period prior to conception. 
Results were analysed by the standard $\chi^{2}$ methods appropriate to contingency tables.

One of the authors (DM) was present while the questionnaire was being completed to help clarify problems with interpretation of any of the questions.

\section{Results}

Classical migraine was found to be significantly more prevalent in the lupus group $p=0.05$ (Table 1). Common migraine was less frequent in the SLE group than in the controls, though not to a statistically significant degree. In addition 3 of the SLE patients described visual manifestations suggestive of a migrainous phenomenon (flashing lights in one half of the visual field) but no accompanying headache. No similar episodes were recorded in the control group. The age of onset of classical migraine in the SLE patients ranged from 8 to 44 years (mean $26 \cdot 7$ years, SD $13 \cdot 1$ years), while in the control group the range was 12 to 21 (mean 16.6 years, SD 3.2 years). The difference in the means was not statistically significant. Further details of the age of onset of migraine in the 2 groups are shown in Table 2.

No significant difference in the existence of a family history of migraine was evident in the 2 groups (Table 3). It was not possible to distinguish accurately in retrospect the different types of migraine in the family and they were therefore considered collectively. None of the lupus patients or those in the control group with any sort of migrainous phenomena were currently on the contraceptive pill.

Table 1 A comparison of the number of subjects with clinical and common migraine in the SLE and control groups

\begin{tabular}{|c|c|c|c|}
\hline \multirow[t]{2}{*}{ No. of subjects } & $S L E$ & Control & $p$ value \\
\hline & 30 & 30 & \\
\hline $\begin{array}{l}\text { Classical migraine } \\
\text { Common migraine } \\
\text { Visual disturbance only }\end{array}$ & $\begin{array}{r}12 \\
2 \\
3\end{array}$ & $\begin{array}{l}4 \\
5 \\
0\end{array}$ & $\begin{array}{l}0.05 \\
0.4 \\
0.2\end{array}$ \\
\hline
\end{tabular}

$P \leqslant 0.05$ is regarded as statistically significant.

Table 2 The temporal relationship between the onset of migraine and diagnosis of SLE

\begin{tabular}{lll}
\hline & \multicolumn{2}{l}{ No. of patients with } \\
\cline { 2 - 3 } & $\begin{array}{l}\text { Classical } \\
\text { migraine }\end{array}$ & $\begin{array}{l}\text { All types } \\
\text { migraine }\end{array}$ \\
\hline Onset 1-5 years before diagnosis of SLE & 3 & 5 \\
Onset over 5 years before diagnosis of SLE & 4 & 5 \\
Onset 1-5 years after diagnosis of SLE & 3 & 5 \\
Onset over 5 years after diagnosis of SLE & 2 & 2 \\
\hline
\end{tabular}

Table 3 Frequency of a positive family history of migraine in the SLE and control patients

\begin{tabular}{lllll}
\hline & $\begin{array}{l}\text { Patients with } \\
\text { no migraine } \\
\text { themselves }\end{array}$ & $\begin{array}{l}\text { Patients with } \\
\text { classical } \\
\text { migraine }\end{array}$ & $\begin{array}{l}\text { Patients with } \\
\text { common } \\
\text { migraine }\end{array}$ & $\begin{array}{l}\text { Patients with } \\
\text { visual aura } \\
\text { only }\end{array}$ \\
\hline Controls & $20(4)$ & $15(1)$ & $5(3)$ & - \\
SLE & $13^{*}(1)$ & $12(2)$ & $2(0)$ & $3(1)$ \\
\hline
\end{tabular}

* One patient in this group did not know whether any member of her family had migraine or not. The number of patients in each group with a positive family history of migraine is shown in brackets.

Table 4 Frequency of Raynaud's phenomenon occurring in the SLE patients with and without migraine

\begin{tabular}{llll}
\hline SLE patients & $\begin{array}{l}\text { With } \\
\text { Raynaud's } \\
\text { phenomenon }\end{array}$ & $\begin{array}{l}\text { Without } \\
\text { Raynaud's } \\
\text { phenomenon }\end{array}$ & Total \\
\hline With classical migraine & $5(9)$ & $7(8)$ & $12(17)$ \\
Without classical migraine & $8(8)$ & $5(5)$ & $13(13)$ \\
Total & $13(17)$ & $12(13)$ & $25(30)$ \\
\hline
\end{tabular}

The figures in brackets refer to all types of migraine.

Eight patients in each group with migrainous phenomena had previously used oral contraception.

Out of the 7 lupus patients whose classical migraine antedated the diagnosis of SLE 3 subsequently noted an increase in symptoms with the onset of the disease. In 2 patients no change occurred after the onset of SLE, while 2 patients noted an improvement in their symptoms. Only 2 out of the 12 patients with classical migraine in SLE noted any increases in symptoms in association with flare of disease activity. One of the 2 patients with common migraine and SLE but none of the 3 with simple visual disturbance noted any increase in symptoms.

An attempt was made to correlate the frequency of migraine headaches with Raynaud's phenomenon (Table 4). Patients with SLE and Raynaud's phenomenon were no more likely to experience classical or common migraine than patients with SLE without Raynaud's.

\section{Discussion}

A recent list of the neurological manifestations of $\mathrm{SLE}^{4}$ fails to mention migraine. However, both Friedman ${ }^{5}$ and Hughes ${ }^{6}$ have claimed that migraine occurs frequently in SLE. The relatively high prevalence of migraine in a normal population suggested the need for a controlled study in patients with SLE to determine the significance of these previous observations. The prevalence of migraine in the general population has been reported as high as $29 \%$ in females, though Brandt and Lessell in an uncontrolled study found a prevalence of $5 \%$ in 1100 patients seen in a rheumatology clinic. In the present 
study $30 \%$ of our control group had some form of migraine (15\% classical and $15 \%$ common migraine). Waters has discussed ${ }^{8}$ the possible reasons for the variation in the reported prevalence of migraine.

The prevalence of classical migraine in this study was significantly increased in the lupus group. There appeared to be no association between the frequency and severity of classical or common migraine with disease activity. Brandt and Lessell ${ }^{1}$ reported that in their patients migrainous symptoms were commonly associated with exacerbations of SLE and in some cases responded to corticosteroid therapy. A controlled prospective study would be required to confirm these observations. Raynaud's phenomenon is common in $\mathrm{SLE}^{3}$ (Table 4). The severity of Raynaud's phenomenon did not correlate with the frequency and severity of classical or common migraine. It was considered that small-vessel disease might underlie the clinical phenomena of SLE, including Raynaud's disease, and contribute to the cerebrovascular mechanism causing migraine. ${ }^{9}$ Despite the lack of correlation between exacerbation of lupus and Raynaud's phenomenon in the present study it seems reasonable to suggest that any young female patient with migraine and Raynaud's phenomenon should be further investigated to exclude SLE.

Oral contraception was not associated with an increased prevalence of migraine in the SLE patients compared with controls. There was no difference in the frequency of a positive family history of migraine between the patients and controls. These observations would support the clinical impression that there is an increased prevalence of migraine in SLE and that it may be part of the disease process. However, unlike Brandt and Lessell ${ }^{1}$ we did not exclude from the present study patients with a family history of migraine or a history of migraine commencing during or before adolescence. It is assumed that these authors excluded such cases in order to study those patients with SLE whose migraine was not likely to be inherited or occurring by coincidence, adolescence being a common period of onset for migraine. If patients with a positive family history of migraine or an onset during or before adolescence are excluded from the present study, there were 7 out of 30 SLE patients and one out of 30 controls with classical migraine $(p=0.05)$. Considering classical and common migraine and those with a visual aura together, and excluding the same groups, we find there were 10 out of 30 SLE patients and 4 out of 30 controls $(p=0 \cdot 1)$. Thus classical migraine occurs more frequently in the lupus patients. However, the justification for excluding these 2 groups of patients seems questionable, since not everybody with a family history of migraine will necessarily develop it and lupus itself can start in adolescence, in which case any migraine headaches may be related to the disease.

It may be that the reported increased prevalence of migraine in SLE is a nonspecific result of the stress associated with the disease or its treatment. The possibility remains, however, that migraine in SLE may in part be determined by the underlying disease process. Thus the clinical phenotype of migraine may be determined by more than one pathogenetic mechanism.

D.A.I. is a Sir Jules Thorn research fellow.

We thank Mrs Jane De Stoop for typing the manuscript.

\section{References}

1 Brandt K D, Lessell S. Migrainous phenomena in systemic lupus erythematosus. Arthritis Rheum 1978; 21 : 7-16.

2 Atkinson R A, Appenzeller $O$. Headache in small vessel disease of the brain. A study of patients with systemic lupus ery thematosus. Headache 1975; 15: 198-201.

3 Cohen A S, Reynolds W E, Franklin E C, et al. Preliminary criteria for the classification of systemic lupus erythematosus. Bull Rheum Dis 1971 ; 21 : 643-8.

4 Lessell S. Some ophthalmological and neurological aspects of systemic lupus erythematosus. In SLE Symposium. J Rheumatol 1980; 7: 398-403.

5 Friedman A P. Headache. In: Baker A B, Baker L M, eds. Clinical Neurology. Hagerstown: Harper and Row, 1976: 2: 7 .

6 Hughes G R V. Central nervous system lupus-diagnosis and treatment. In SLE Symposium. J Rheumatol 1980; 7 : 405-11.

7 Waters W E, O'Connor P J. Prevalence of migraine. $J$ Neurol Neurosurg Psychiatry 1975; 38: 613-6.

8 Waters W E. Review of previous surveys of headache and migraine. In: Waters $\mathrm{W} \mathrm{E}$, ed. The Epidemiology of Migraine. Bracknell: Boehringer Ingelheim, 1974: 11-13.

9 Dalessio D J. In: Bronica J J, ed. Advances in Neurology. New York: Raven Press, 1974; 4: 395-401. 